iliac fossa and has been thought to arise from an inflamed appendix, careful manipulation during the $x$-ray examinations may show that the appendix itself is quite free from tenderness to pressure, while some portion of the terminal coil of the ileum is the seat of the tenderness. The usual points at which tenderness is found along the terminal coil of the ileum are three: (1) The point at which the terminal coil of the ileum crosses the pelvic brim ; (2) the ileo-caecal entrance; and (3) the seat of an ileal kink when one is present.

\section{The Ileal Kints.}

Mr. Moynihan stated recently ${ }^{5}$ that " he had very rarely found an ileal kink, and never without the plain evidence of an appendicitis, to which he believed the link to be secondary." As a matter of fact the typical ileal kink, of which I have now seen many examples (see Figs. 5, 5A, 11,16 , and 17), has no connexion whatever with the appendix ${ }^{16}$ unless quite accidentally, as in Fig. 15, ivhere the ileum and the appendix are kinked by the same band. I have described the ileal kink elsewhere, ${ }^{16}$ and there is no need to repest the description. The appendix is quite separate from the ileal end coil ; I have seen this clearly demonstrated at numerous operations, and I have given several instances in the present communication (Figs. 5, 11 13,16 , and 17).

The anatomical relations of the parts concerned in ileal kinking have been carefully described and beautifully illustrated by several American sürgeons, 78910 "who are now carrying out Mr. Lane's operation of "short-circuiting" for the curo of intestinal stasis with most satisfactory results.

Intestinal stasis forms one of the most important and far-reaching branches of radiographic research, and the systematic investigation of the alimentary tract by the $x$ rays after a bismuth meal is rapidly becoming an essential preliminary to intestinal surgery, and indeed to medical treatment of the digestive system.

REFERENCES.

1 Radiography in Intestinal stasis, Lancet, December 30th, 1911 , and Proc. Rny. Soc. Mel. December, 1911. 2 Duodenal Obstiction as Shown ly Radiography, Burrst Mepical JoonNat, May 20th, 1911: "Some Points in the Diagnosis and Treatment of Chronic Duodenal Ulcer, Lancet, January 6th, 1912 . 4 Jejunal and Gastro-Jejunal Ulcers, Symploms and Signs in some Abdominal Diseases, British Medić JotrNat, February 17th, 1912. "6 Radiographic, Demonstration of Lane's Ileal Kink, Practilioner, April, 1911. 'Tranklin H. Martin, Surgery, Gymaecology, and Obstetrics, January, 1911, p. 34.8 Chas. H. Mayo, ibid., March, 1911, 1). 227. 9 F. Gregory Connell, ibid., Norember, 1911, 1. 485. ${ }^{10}$ Geo. Tulley Vaughan, ibid., February, 1912. ${ }^{11}$ Chronic Intestinal Stasis. W. Arbuthnot Lane, Britisf Medical Jouriai May 4th, 1912, pp. 991-2. 12'R. Murray Leslie, Clinical Journti, May lst, 1912

\section{THE AUTOINOCULATION TEST IN TUBERCULOSIS.*}

\author{
BY H. WARREN CROWE, M.D.OxoN., \\ YELVERTON, DEVON.
}

Is 1906 Wright $^{1}$ described spontaneous fluctuations of the tuberculo-opsonic index in febrile cases of tuberculosis and affirmed the possibility of determining whether any given fever were associated with the tubercle bacillus, by observing a series of indices, and marking the presence or absence of thes fluctuations. The explanation Wright gave of this phenomenon seems quite convincing. He postulated a periodic change in the amount of toxic products entering the blood from a diseased focus. By day increased movement and bodily activity would, even when a patient was confined to bed, result in an increase of the blood flow throngh the whole organism, and toxic material would be washed out the more readily from the focus of disease into the general circulation. To this the system must respond by an increased production of immune substances. Hence come the fluctuations in the tuberculo-opsonic index, which, in point of fact, is an indicator of the amount of such response. To this periodic flow of toxic material Wright applied the term "spontaneous autoinoculation."

Freeman ${ }^{2}$ found that massage applied to a diseased joint was followed by an increased amount of toxin in the circulation, demonstrable again by a very definite

Read in opening a discussion at the Plymouth Medical Sociely on the diagnosis and treatment of tuberculosis. fluctuation in the opsonic index, provided only that the index was determined in respect of the causal organism. This he termed an artificial or induced autoinocnlation, and he was able to utilize his discovery to elucidate the nature of joint troubles of doubtful origin. The example he first quoted was that of a knee-joint said to be tuberculous; after massage the tuberculo-opsonic index did not fluctuate, whilst the index determined in respeet of the gonococcus gave a mirked and typical fluctuation. The inference drawn by Freeman was that the disease must bo gonorrhoea! and not tuberculous.

Hereupon Wright an 7 his collaborators, ${ }^{8}$ following out the same line of experimentation, showed that a very considerable number of agencies, such as exercise, ope:a tion, Bier's bandage, and even physical examination of the chest, were capable of inducing atutoinoculation.

Patterson elaboratel his treatment for phithisis, consisting of the scienti ic induction of autoinoculation by carefully graduated lakour, and in connexion therewitl Inman ${ }^{4}$ found that as long as disease was still present the varying grades of work produced fluctuations in the opsonic index, whilst in thosa apparently cured the most arduous labour was followed by no fluctuation whatever.

Lastly, I may refer to Inman's recent paper, ${ }^{5}$ in which he gives the result of 100 consecutive autoinoculation tests undertaken as a means of diagnosis in cases suspected of phthisis. These tests, however, suffer considerably from the fact that the exercise which was to excite an auto inoculation was frequently insufficient. : It is essential that in all tests undertaken for diagnosis this source of error should be rigorously excluded, and as our experience has grown it can now be: claimed that such is the case.

The apparatus which $I$ now use is a copy of the one suggested by Dr. Willcox for testing the lungs at St. Mary"s Hospital. By its moans forced respiration continued orer a period of some minutes can be used to induce auto inoculation in a tuberculous lung. The presence or absence of such antoinoculation is then determined by measuring the opsonic index before and at varying periods after the exercise.

Now there is a large number of diagnostic tests for tuberculosis, and it is difficult to decide which is the best unless one has some definite notion of the fumetion and characters which such a test should possess.

It would seem, therefore, to be of advantage to formu. late some standard whereby the merits of every test may be adjudicated. A little thought will give us certain canons to which an ideal test should conform. First, it must be harmless; secondly, it must confine itself to pointing ont the presence of active or smouldering tubercle -it must not be too penetrative; thirdly, the answer given be it must be unmistakable; fourthly, it must be universally applicable; fifthly, it must be simple ; sixthly. it should be practicable after treatment to determine the time when cure is complete; and, lastly, the ideal tost must be infallible. Of these saven canons, then, it will hardly be denied that the first and the last are the most important. Harmlessness and infallibility must be our watchwords in the search-the touchstone of our success.

In the series of 61 autoinoculation tests which form tho basis of this paper, I have excluded none that have been undertaken for phthisis during the last three years; 23 are crucial cases in which diagnosis of tuberculosis was to be definitely made or denied. In each case a definite answer was given, and in no case, so far, have I had any evidenco that the verdict was wroug. The following are examples:

Test 1.-A girl, apparently in quite an advanced stage of phthisis, was sent to Dartmoor by a London specialist with an extremely bad prognosis. In all good faith I treated her rigorously for lung disease. The course of the case, however, threw some doubt on the diagnosis, and it seemed advisable to take steps to decide the question. With a view to obtaining evidence as to the possibility of inducing autoinoculation, she was maide to walk for two hours. The opsonic index remained normal. The test was repented, with the same result. Thereupon further treatment was discontinued, and this somentrat hrsterical invalid was told to lead an ordinary life. No further symptoms have developed.

T'est 2.-A young woman, four months after an attack of influenza, had a slightly raised temperature at night, but showed no physical signs. She was made to walk two miles, and the index was determined of specimens of blood taken before, one hour after, six hours after, and again the next morning. The readings were: $0.85,1.15,0.7$, and 1.3, an immediate rise, followed by a fali, and then a second rise. This is a typical result whęre tubercle is present. I had no 
hesitation in giving a positive answer, and the patient went to a sanatorium, whence, after three months, she was discharged cured. The obvious criticism might be raised that phthisis was not actually demonstrated. Clinically there was a doubt, yet, as a mattar of fact, to-day she is in berl with fever, sweats, cough, an ll loss of weight, and her doctor writes that he is most anxious as to her future.

T'sts 3 and 4.-Two parallel cases of swollen joint s came up for diagnosis. In each case massage was cmployed as the cxciting agent, the blood being taken at the usual intervals. In the one case the index fluctuatel, but not in the other. The former was diasnosed as tuberculous, and an arthiestomy, which was later performed, confirmed the opsonic finding, whereas the latter showerl a steady normal index and was treated successfully by massage.

Test 5.-A lafly suffered from colitis and abilominal pains, continually referred to the appendix region, although the appendix had alrealy been successfully removed. The possibility of tuberculosis was to be exclucled. The ablomen was massaged for about half an hour, and the index taken an liour later. It was found to be normal, and although only one index was taken, it was considered that there was no tuberculous trouble. This was four years ago, and the diagnosis has been upheld by subsequent events.

Tesequent events.

Tests $6,7,8$, and 9.-These are four suspicious cases in which was disappointed not to find a flactuation in the index. My personal bias, if that is a factor in incex determination as opponents of the method claim, was all in favour of diagnosing taberculous misshief. One patient hal an elevation of temperature in the evening, with night sweats and loss of flesh; another was languid and also losing weight after a series of bad colds lasting throughout one winter; a third had nursed a tuberculous sigter and had been warned by Hugsard of Davos to be carefal, she also had suspicious physical signs; whilst the fourth had what seemed quite definite apical phthisis, was cyanotic, and grew tire:l on the slightest provocation. All these gave no fluctuation in the inclex. The test was negative, taberculosis was excluded, and none of them has as yet falsified this prognostication, although from twelve months to three years have passed.

Test 10.-A stoker was invalidet from the navy for phthisis. Signs were so slight that an autoinoculation test was made to confirm the diagnosis. He walkel six miles. The index an hour later was 1.8. This being quite conclusive, he was treated, and later definite signs appeared.

Test 11.-A young child had a gland in the neck in conjunction with an enlarged tonsil. It was found to be tuberculous, since half an hour after massage the index was 0.65; after twenty-four hours it was 1.5.

Te;t I\%.-A phthisical pátient developed hjarseness. To determine whether the laryngitis might be tubsrculous she read aloud for half an hour. The index before rearling was normal, an hour later 1.02 , six hours later 1.04 , and the next morning 1.05. The result of the test was, therefore, negative, and the subsequent course of the case confirmel the diagnosis here made, as her temporary catarrh rapilly disappeared;

Test 13. - A patient came under. review suffering from a cold on the chest. Certain indications suggested the possibility of phthisis. A diagnostic test was undertaken. Readings of the index were 1.1 before the walk, $1.2,0.3,0.75$ at intervals afterwards. He was sent to hospital and died from an acute wards. He was sent to hospit

Test 14.-A child, who had been ill for some monsh with pyaemia. developed a swelling of the ankle-joint. It was thought that the joint might be tuberculous. To decide the question, ten minutes' gentle massase was given. The index to staphylococci varied from 1.0 to 1.45 two hours later. The index to tubercle-bacillas was corstant at 1.3. 'It was inferrect that the ankle was affected by staphylococci, but that the child was somewhere affected by tuberculosis. Later pus containing was somewhere affected by tuberculosis. Later pus containing
staphylococci was obtained from the ankle-joint, and the child eventually died of tuberculous meningitis.

Test 15.-A lad developed a massive pleural effusion. On aspiration the fluid was found to be sterile. There was no fluctustion in the opsonic index after heavy breathing exercises. It was decided that tuberculosis "was not present, and during the last two years no further signs have developed. 'The effusion cleared up after treatment by a dry dietary and copious saline purgation.

Though the series of cases, of which the foregoing are examples, are insufficient to lead to a dogmatic conclusion, yet the percentage of crror liaving been reduced to vanishing point, one may perhaps feel justified in hoping that further trial will establish the extreme reliability of the autoinoculation test.

How doos this test conform to the canons laid down?

1. Harmlessness.-From my own experience I have only once been able to convict the method of having been the cause of increasing the disease, but in that case, shortly to be mentioned, it was certainly rather my inexperience than the nethod which was really at fault.

2. Is the Test too Penetrative?-In comparison with other tests, and $I$ am thinking move especially of the cutaneous and the percutaneous tests, it can be olainer that it is not. One has only to read the recerds of these to see that undci certain citchostances a positive uesult is given in cases of apparently perfect health, in which after- wards no disease has developed. Bandelier and Roepke may be quoted as the best authorities on the tuberculin tests. In regard to the tost of von Pirquet, they use theso words :

The positive cutaneous reaction gives no information as to the character of the tuberculosis, its activity, or the reverse ; reactions occur not merely in cases of manifest tuberculosis but in those where there is olinically no suspicion of tubercle. It only indicates that the body somewhere and somewhen has been infected with tubercle bacilli.

In regard to Calmette's test they also say that stress must be laid on the anatomical standpoint pather than on the clinieal. These tests, then, are too penctrative for practical use. They are evidence of the tubercle bacillus somervlicn and somewhere. But the clinician craves for information as to whether it is now and liere, where perchance the symptonis point. This the autoinoculation test can tell him, for it can be applied for suspested lung disease to the lung, for joint disease to the joint, and for. glandular trouble to the glands, and the fallacy introduced by some insignificant deposit of tubercle elsewhere is avoided.

3. Is the Answer Unmistakable?-Here the hypothetical ground on which tho test is performed must be taken into, account. It depends on an artiticial disturbance of the focus of disease. Granted that this is efficient-and experience must cause us more and more to understand the factors which lead to an efficient autoinoc̀ulationthen I think it may be said that the answer is unmistalsable, and that at the first. attempt, not at the third or fourth, as must be the case before a negative answer can be accepted, when, for instance, old tuberculin is injected.

4. Universal Applicability.-Here, one must admit, the test fails. Theoretically perfect in this respect and in the fact that the test can be extended to embrace the diagnosis of many other conditions besides that of tuberculosis, yct in practice the test fails on account of the time and apparatus required-that is, on account of the expense.

5. Simplicity.-Here, again, the same considerations are involved in the laboratory part of the test. The technique is difficult. None more so. But as regards the trouble given to the patient and the supervision required, then one can claim that this test is as simple as most of the tests. All that is involved is the act of producing an autoinocula tion and the taking of a few specimens of blood, which most patic $n$ s can do for themselres. Compare this with the prolonged observations which are necessary to exclude tuberculosis in the old tuberculin test.

6. Can the Completion of the Cure be Determined b! this Test?-This brings me to a second scries of tests, which were undertaken to elucidate this very point. The following cxamples speali for themselves. Let it be understood that the test in such casos must always be as severe as possiblc, so as to expose the slightest trace of dissase which may siill be remaining.

T'est 16.-A young wom an t:eated herself at home after a course at a sanatorium. The test to determine whether. she might live a more ordinary life indicated the continued presence of a tuberculous focus, although the patient was apparently perfectly well. The verdict was confirmed two years later, when I was called in to see her in an attack of what she called acute gastritis, and wlien I found a cavity at the left apex discharging numbers of tubercle bacilli.

T'st 17.-A man with slight apical trouble came under treatment for some four mouths. It was necessary to decide the earliest possible moment at which it might be safe for him to return to his work in an office. The test was a nine-mile walk taken very fast. There was no fluctuation in a somewhat low index. He has been at work from that time, now three years ago, without sign of a relapse.

Test 15.-A clergyman suffering from tuberculous laryngitis was considered to be cured. His test was to read a newspaper aloud in his best pulpit manner for an hour. The index readings were $1.0,1.3,1.05$, and 1.6 -a marked fluctuation. Permission to resume work was withheld.

T'est 19.- The patient diasnosed by Test 10 after treatment for some time was sent for a long walk. The inclex before was 1.2 , after 2.1 , six hours later 1.2 again, and twenty-four hours later 1.3. The cure was not yet complete, therefore treatment was continued:

Test 20 .--Small nodules were left after inoculation treatment in a case of mastitis. Could treatment be discontinued? The breast was massaged and the opsonic index determined. The readings were $1.5,0.9$, and 1:4: The cure wots not complete:

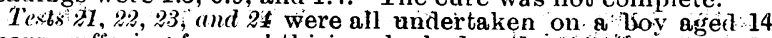
years, suffering from phthisis, who had under treatment made renrarkable progress. He went-to Switzerland to "hardetrotf." On his return he was given a test of a sixteen-mile walk index before the walk was 1.0 , an hour later 1.1 , six hours later 
0.9 , twelve hours later normal again. There was, in fact, but slight fluctuation, yet as it was in the direction of a rational curve, it was consiclered-that there was a slight trace of phthisis remaining. He was told that if he avoided being overtire 1 he would probably suffer no further from the disease. Twelve months later he took to his bed with an attack of influenza, and for some weeks his temperature at night refused to go down to normal. The question to decide was whether this indicated a recrudescence of his old trouble. He got up and walked one hundred yards. The index did not fluctuate from normal. The test being so slight it was decided that he should now get up daily and that later a second test should be undertaken after he had walked three miles. The index again did not fluctuate, and he was advised to disregard the temperature. After a short time he was quite himself again. Twelve month later he had another attack of influenza. His parents, being rather nervous, decided to have another test performed. This also proved negaive and up till now (two years) the boy negative, and up till now (two years) the boy has continued quite well. He higs taken no particular care of himself and has gone in for all
sports at his school, where recently he won the quarter-mile race.

Test 25.-After three months in a sanatorium a patient with slight apical phthisis underwent a test by a sharp walk for two hours. The index, slightly below normal. did not fluctuate. She was advised that she was cured. She continued quite well unitil twelve montlis later, when she had an attack of influenza: Her old trouble now started afresh. In the result, then, this test proved to be wrong. This is the only: failure which I have to record. There is no doubt that I was at fault, rather than the method, in that $I$ did not provide a sufficiently severe test to disturb the focus of her disease. I do not think that such an error can occur in the practice now in use of forced respiration against a load, as in the water bottles already mentioned.

7. Infallibility.-In respect of this, the most important of all, the series of cases speak for themselves, but I may pérhaps quote the woids of Sir Almroth Wright in regard to the point. He says ${ }^{2}$ :

We have by . . methods of artificial autoinoculation, combined in each case with measurement of the opsonic index before and after such event, obtai e diasnostic results which have up to the present incuriabl, be a borne out by the subsequent history of the case.

And he then goes on to explain that this test can be used for the elucidation of many problems in the treatment of a patient during the course of his illness.

The remainder of my tests were carried out with a view to deciding such problems. The chart represents graphically a dozen tests carried out on a girl suffering from spinal disease (sèe chart). The numbers refer to the chart :

I.-May 21st, 1908. After tuberculin treatment for some weeks, the temperature being normal and there being no discharge from a sinus, was it safe for her to get up? She was up for ten minutes. The resultant curve shows a prolonged negative phase. The temperature rose the next day and continued high. The girl was very ill for months, and had a large psoas high. The girl was very ill for months, and had a large psoas absess on each side. This is the unfortunate case I mentioned, where one must ascribe her subsequent illness to an auto-
inoculation test. In the light of later experience it is clear that a preliminary test of a much less severe character ought to have been undertaken.

II.-May 14th, 1909. A year later she stood up again, but this time in a spinal jacket, the slight variation suggested caution. She was kept at rest for a few weeks longer. Then

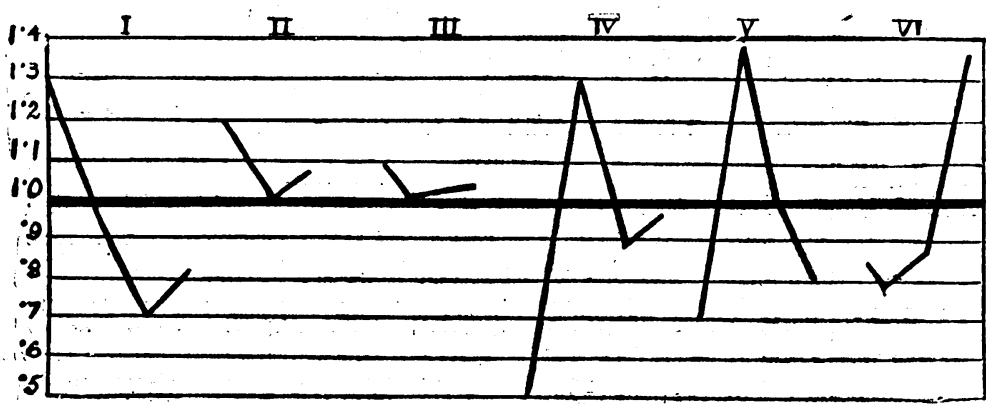

The first and last of these show but little effect, whilst VIII, on account of the negative phase, indicates that the walk was excessive

X.-In March of 1911 the girl seemed to be perfectly cured, and the problem presented itself as to whether it might now be safe to leave off the spinal jacket. I decided to test this question, and under my own eye, the patient coming over by train for the purpose, I had the jacket taken off, and made her walk across the room and back asain. 'The resultant opsonic curve shows a negative phase lasting until the next morning. The jacket was liept ov.

XI.-In June, however, when the test was repeated, no altera tion was discovered in the index. She was then told to leave it off, and gradually to increase thé len goth of her daily walk.

XII.-A month later I tested the blood in connexion with a considerałble wâk; and; finding no immunity response, arguer that the focus of disease was extinct. I told hei that she might consider herself cured, and lead an ordinary life. During the latter days of October I heard from her that she was keeping perfectly well, so that I have hopes that the index will justify its prognostications in this case as in the others."*

Other examples of problems in treatment are provided by the following tests:

Test 26.-A phthisical patient with a slightly elevated temperature should he get up? In order to test this point he was made to rise and go downstairs, move about, and then return to bed. The index remained constant at 0:91: The answer given was that he might safely leave his bed: In the result his condition improved; and his temperature fell to normal.

Test $2 \%$. -The patient desired to play golf. Was it safe for him to do so? He tried a few holes. His index before was 0.65 , an hour later 1.2 , six hours later 0.65 , and the next day 1.5 . Obviously the exercise-had caused a considerable amount of atoinoculation. He was told to avoid strenuous exercise.

Test 28. - How far might this same patient walk? His usual distance was slightly increased; and it was found that the index fluctuated considerably. He was told that it was dangerous for him to walk farther than was at that time his custom.

I'st 59 .-A lady suffering from phthisis, complicated by a tuberculons. kidney, was anxious to walk. . The index did not fluctuate after a short turn; consequently permission was given.

Tests 30 and 31.-A man suffering from extremely chronic phthisis had improved steadily under a healthy régime. Tests phthisis had improved steadily under a healthy régime. Tests
were undertaken to determine how far he were undertaken to determine how far he could walk; and whether he could, without
harm, make excursons by train. The index did not fluctuate with any amount of walking, but when an excursion involving a considerable amount of fatigue was undertaken the index fluctuated between 0.9 and 1.7. From these two tests the patient's immediate future was tests the patient's
definitely mapped out.

In conclusion, then, my own experience, drawn from some 60 odd tests, leads me to form an extremely high opinion of the value of this method. It will be a matter for sincere regret if the difficulty of the opsonic technique, combined with the carping criticism of a section of the scientific

we tried again, III, and even allowed her to take a step or two. The resultant variation was so slight that it seemed safe for her to be moved by train to her home in North Devon.

IV.-As a precautionary measure, I examined the index curve during the three days following her return home. It will be noticed that the variation is wide, but there is no marked negative phase. She was told to rest for a while pending the result of a further test.

$\mathrm{V}$ and VI.-Both taken to determine the effect of walks of varying distanco. Curve $V$, the flrst short walk, shows only a world, who either do not take the trouble or are quite unable to conquer that technique, should delay a general recognition of the fact that in the Wright-Freeman

* May, 1912. This patient has relapsed notwithstanding the readings of tho index. She underwent a severe strain in connexion with the accidental desth of a friend. Wibhin a few weeksia fresh psoas abscess was found. It is clear that the focus was not completely extinet, although the index did not fluctuate. The obvious explanation is

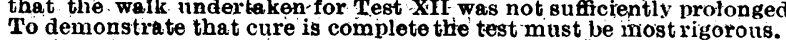


antoinoculation test we possess the means of diagnosing tuberculosis in its earlier stages, of the further fact that this test is so extraordinarily reliable, that on its verdict alone treatment may be confidently applied or as confidently omitted, and, lastly, of its utility in dirccting the course of our treatment and of deciding the moment when cure is complete.

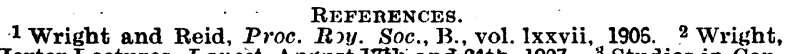
Herter Lectures, Lancèt, Angust 17th and 24th, 1907. 's Studies in Connexion with Therapeutic Inununization. Wright, Douglus. Fr-cman, Inman, Lancet, January $25 \mathrm{th}, 1908$. 5 Inman, Lancet, December 17th, Inma.

\section{THE PATHS OF RHEUMATIC INFECTION AND THEIR PROTECTION IN CHILDREN.}

\section{BY \\ J. ROSS MACKENZIE, M.D.ABERD., ABERTILLERY, MON.}

ThE admirable work of Drs. Poynton and Paine has clearly demonstrated that a micrococcus, possessing distinct morphological characters, can be isolated from the tissues of the rhermatic patient, cultured on nutrient media, inoculated into animals, producing anatomical lesions identical with those found in acute rheumatism; and further, that this microcoscus can be isolated in pure culture from the blood and tissues of these infected animals, completing the essentials of bacteriological science. The researches of Drs. Poynton and Paine, ${ }^{1 .}$ Beattie, ${ }^{2}$ Ainley Walker, ${ }^{3}$ D. B. Lees, ${ }^{4}$ Apert, ${ }^{5}$ Wassermann and Malkoff, Dana, ${ }^{7}$ and others have done much to dissipate the scepticism manifested as to the identity of tho Micrococcus rheumaticus. The paths by which the specific agent finds access to the system as well as the prevention of such invasion still demand attention.

\section{Throat.}

(a) Local Invasion.

The most important, as woll as the most frequent, path of infection is undoubtedly the throat. It is occasionally difficult, however, to decide that dirfuse congestion of the tonsils and pharynx have any connexion with the rhenmatic agent, even when the manifestations of rheumatic toxaemia aro more or less general. A relationship is at once suggested by the large percentage of children suffering from rleumatic phenomena who, at the same time, present enlarged tonsils and hypertrophied tissue in the nasopharynx. The contention that such a condition of the throat increases the susceptibility to rheumatic infection is rational, but enlarged tonsihs never produce rheumatism until they become infected, with the specific agent, and even then the infective agent may remain localized in the tonsils or pharynx, producing toxins which are projected into the system in variable quantities and at variable intervals. This, I think, accounts for my frequent failures to find the Micrococcus rheumaticus in the blood, and also for the erratic behaviour and latency of rheumatic manifestations in children.

There is evidence accumulating which goes to show, further, that in the absence of hypertrophied adenoid tissue in the throat or naso-pharynx there is irequently inflammatory congestion in the region of the soft palate, pillars of the fauces, and pharynx (Holt, ${ }^{8}$ Hutchison,${ }^{9}$ and Cheadle ${ }^{10}$ in the earliest stage of rhenmatic infection, and from such a rheumatic throat the micrococcus has been isolated by Poynton. ${ }^{1}$

\section{(b) General Infection.}

It has been suggested that the infective agent finds entrance from the throat to the general system through the lymphatics. In many cases the lymphatic glands at the angle of the jaw are enlarged, indicating infection of the lymph channels, due, however, not to the absorption of rheumatic infection through the lymphatics, bui to enlarged and infected tonsils. In the purely rheumatic throat the lymphat:c glands are not enlarged. This fact, together with the evidence that the $M$. rheumaticus has an affinity for the endothelial cells lining the capillary blood vessels, and the sudden onset of acute rlreumatic phenomena when the infective agent comes in contact with an injured surface, force me to the conclusion that the path from local invasion to general infection is direct into the blood stream and not through the lymph channels.

\section{CASE I.}

A girl, aged 9 sears, previous to the operation of tonsillotomy was in excellent health, presenting only. the usual signs of enlarged tonsils and adenoids. Within a few hours of the operation she ccmplained of pains in the knees and ankles. The temperature was then $99.5^{\circ} \mathrm{F}$. and the pulse 100 . Next day the temperature was $101^{\circ} \mathrm{F}$., pulse 120 , and there wais marked pain and tenderness with effusion into the knee-joints and pain in the elbow-joints. The symptoms subsided after some days under soi ium salicylate, but not before cardiac dilatation had supervencd. This case may seem a prre coincidence, but $I$ have had sir ilar experience on several occasions, and the interpretation of this sudden onset of rheumatic phenomena is, I consider, the d st:arbance of a local and latent focus with rapid absorption of the micrococcus into the circulation from the bleeding surface of the tonsillar bed or the pharynx. It is interesting to note (1) that a swab taken from the throat and smeared upcn agar, blood serum, and gelatine, gave on each a culture of staphylococci ; (2) that a particle taken with aseptic precautions from the centre of the left tonsil after enucleation precautions from the centre of the left tonsil after enucleation cocci in short chains.

To emplasize this point I record here four consecutive eases. They are important inasmuch as none of them, apart from occasional attacks of sore throat and growing pains, exhibited other than the concomitant signs of hypertrophied tonsils and adenoids. The tonsils, on removal, were put in sterilized bottles. With strict precautions a particle from the centre of each was inoculated in broth. $\Lambda$ fter thirty-six hours' incubation films were made, and stained with methyl thionine. A more or less pure culture of streptococci in short chains was found in each case, while on some films were seen scattered nodules of lymphoid tissue with numerous cocci arranged in pairs. The microscopical and morphological characters of each culture were compared with those of the original $M$. r.heumaticus described by Drs. Poynton and Paine, and were found to be identical.

\begin{tabular}{|c|c|c|c|}
\hline Age. & $\begin{array}{c}\text { Previous } \\
\text { History of } \\
\text { Rheumatism. }\end{array}$ & Remarks. & $\begin{array}{l}\text { Bacteriological } \\
\text { Result. }\end{array}$ \\
\hline 8 yrs. & Negative & $\underset{\text { throat }}{\text { Frequent }}$ sore & $\begin{array}{l}\text { Pure culture of cocci } \\
\text { in short chains with } \\
\text { diplococci. }\end{array}$ \\
\hline $6 \mathrm{yrs}$. & $\begin{array}{l}\text { Mild attack of } \\
\text { arthritis } \\
\text { months pre- } \\
\text { viously }\end{array}$ & $\begin{array}{l}\text { Occasional sore } \\
\text { throat and grow- } \\
\text { ing paing }\end{array}$ & $\begin{array}{l}\text { Some staphylococci } \\
\text { with n u merous } \\
\text { streptococci in short } \\
\text { chains. }\end{array}$ \\
\hline 9 yrs. & Growing pains & $\begin{array}{l}\text { Sore tbroat occa- } \\
\text { sionally. So me } \\
\text { deafness from re- } \\
\text { cent otitis media }\end{array}$ & $\begin{array}{l}\text { Pure culture of cocci } \\
\text { in short chains with } \\
\text { numerous diplo- } \\
\text { cocci. }\end{array}$ \\
\hline $10 \mathrm{rrs}$. & Negative & 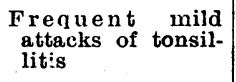 & $\begin{array}{l}\text { Streptococci in short } \\
\text { chains, diplococci } \\
\text { and staphylococci. }\end{array}$ \\
\hline
\end{tabular}

II. Pulmonary Mucous Membrane.

It will not be seriously disputed that many cases of acute and subacute rheumatism in children show no evidence of sore throat, and of late my attention has been directed to the possibility not only of certain mild catarrhal conditions of the bronchial mucous membrane owing thair inception to infection with the Micrococcus rheumaticus, but also to a general infection taking place through the impaired mucons membrane.

\section{(a) Local Invasion.}

Satisfactory experimental evidence of the local invasion of the pulmonary mucous membrane by the Micrococcus rheumaticus in the form of bronchial catarrh or bronchopneumonia is wanting. If a mild bronchial catarrh may proceed to actual bronchitis, and bronchitis to capillary bronchitis and ultimately consolidation of the alveoli, it is difficult to understand why rheumatic bronchopncumonia may not arise in a similar way, and clinically $I$ am persuaded that it does.

CASE II.

A girl, aged 10, was brought to me on account of a persistent cough with occasional muscular and articular pains. There was a history of acute rheumatism and a well-marked family history. No indication of sweating or wasting. The heart was normal, and there was no evidence that this was a throat normal, and there was no evidence that this was a throat cough. The only physical sign found in the chest was a harsh
respiratory murmur more marked on the left side, and esperespiratory murmur more marked on the left side, and espe-
crally between the scapulae and below the angle of the left 